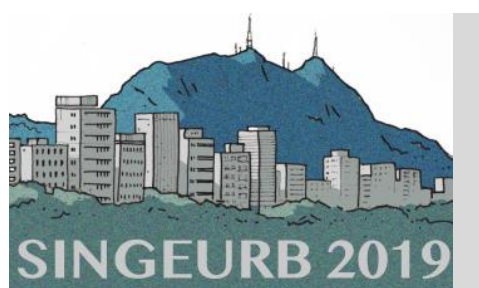

II Simpósio Nacional de Gestão e Engenharia Urbana

ABORDAGEM SISTÊMICA, ESCALAS E INTERSETORIALIDADE: DESAFIOS E POTENCIAIS DO DESENVOLVIMENTO URBANO SUSTENTÁVEL

27 a 29 de novembro - USP

\title{
Concertação Urbanística em Projetos Urbanos: O Caso de Porto Alegre
}

\section{Urban Agreements in Urban Projects: the case of Porto Alegre \\ Steigleder, Annelise Monteiro '; Piccinini, Lívia Teresinha Salomão2;}

' Universidade Federal do Rio Grande do Sul, Porto Alegre, Brasil, annelise@mp.rs.gov.br

2 Universidade Federal do Rio Grande do Sul, livia.piccinini@ufrgs.br

\begin{abstract}
RESUMO
O artigo versa sobre a concertação urbanística como instrumento utilizado para viabilizar grandes projetos urbanos e insere-se em uma pesquisa de doutorado, apresentando análises preliminares coletadas a partir de processos de licenciamento ambiental em tramitação na cidade de Porto Alegre. Por meio de termo de compromisso firmado entre - empreendedor e o Município, são estabelecidas medidas mitigadoras e compensatórias de impactos urbano-ambientais a cargo do interessado no licenciamento do empreendimento. No entanto, a falta de instrumentos de avaliação de impactos urbano-ambientais multi-escalares, que permitam a identificação dos impactos sinérgicos e cumulativos associados aos projetos vem comprometendo a sustentabilidade urbano ambiental e o planejamento integrado do território, e vem criando um mosaico de empreendimentos desconectados, que impactam a infraestrutura, sobretudo viária, e não garantem a justa distribuição dos ônus e benefícios da urbanização. A partir de estudo de caso múltiplo observa-se que a concertação é feita caso a caso, com ampla discricionariedade administrativa, e sem estudos abrangentes que sejam capazes de orientar a tomada de decisões no âmbito da Prefeitura. O estudo versa sobre os Projetos Especiais de Porto Alegre, cujo Plano Diretor, desde 1999, contempla a possibilidade de acordos programáticos para a viabilização de grandes projetos urbanos.
\end{abstract}

Palavras-chave: Concertação Urbanística, Projeto Urbano, Sustentabilidade ambiental.

\begin{abstract}
The article deals with urban concertation as an instrument used to enable large urban projects and is part of a doctoral research, presenting preliminary analyses. Through an

${ }^{1}$ STEIGLEDER, Annelise Monteiro; PICCININI, Lívia Teresinha Salomão. Concertação Urbanística em Projetos Urbanos: O caso de Porto Alegre. In: II SIMPÓSIO NACIONAL DE GESTÃO E ENGENHARIA URBANA: SINGEURB, 2019, São Paulo. Anais... Porto Alegre: ANTAC, 2019.
\end{abstract}


agreement signed between the entrepreneur and the Municipality, compensatory and mitigating measures of urban-environmental impacts are established by the interested party in the licensing of the project. However, the lack of instruments for evaluating urbanenvironmental impacts that allow multi-scalar analysis, able to contribute to the synergistic and integrated analysis of the impacts associated with urban projects; as well as legislation guaranteeing the landscape and architectural harmony between the various urban projects, has been compromising the urban environmental sustainability and the integrated planning of the territory, and has been creating a mosaic of disconnected enterprises that impact the infrastructures and do not guarantee the fair distribution of onus and benefits of urbanization. Based on an empirical study carried out in Porto Alegre, it is observed that, since 1999, the consultation to enable Special Projects is done on a case-by-case basis, with broad administrative discretion, and without comprehensive studies and intermediate plans, capable of guiding the analysis within the scope of the City Hall.

Keywords: Urban agreements, Urban Project, Environmental Sustaintability.

\section{INTRODUÇÃO}

O presente artigo integra uma pesquisa de doutorado em Planejamento Urbano e objetiva investigar, sob a perspectiva jurídica, a concertação urbanística como meio para viabilização de Projetos Urbanos que demandam flexibilização do Plano Diretor, em Porto Alegre, o que é operacionalizado através de um termo de compromisso, em que são estabelecidas contrapartidas a cargo do empreendedor para mitigar impactos urbano-ambientais. A partir de pesquisa em processos administrativos da Prefeitura, constatou-se que a definição das contrapartidas é ajustada caso a caso entre o empreendedor e o Município, o que desafia o Planejamento Urbano, cujo objetivo é propiciar uma abordagem sistêmica, que considere as múltiplas escalas de planejamento e perspectivas de médio e longo prazos (SOUZA, 2015), pois a negociação não é precedida de estudos abrangentes, em escalas que permitam a compreensão das dinâmicas urbanas e a consideração dos múltiplos impactos associados ao projeto.

A metodologia adotada foi o estudo de casos em processos de licenciamento de diversos projetos especiais localizados em uma mesma região de Porto Alegre, todos caracterizados por serem pólos geradores de tráfego. Os aspectos observados foram: os instrumentos de avaliação de impacto utilizados, as formas de participação social e as contrapartidas resultantes.

\section{CONCERTAÇÃO URBANÍSTICA}

A concertação entre os setores público e privado, para viabilização de grandes projetos urbanos, é uma das estratégias contemporâneas utilizadas para imprimir flexibilidade ao planejamento e para financiar a infraestrutura urbana, em um contexto em que os Municípios carecem de recursos para promover o desenvolvimento urbano. Pode assumir a forma contratual ou restar implícita no processo de licenciamento de projetos urbanos (CORREA, 2009). O que se destaca é o "processo", constituído por diversos atos, produzidos ao longo do tempo, cujo conteúdo é especificado na interação entre os agentes públicos, privados (proprietário da terra, incorporadora, arquitetos) e outras entidades interessadas (associações comunitárias, Ministério Público, etc).

O modelo negociado de planejamento urbano é utilizado em países europeus para flexibilizar o planejamento e viabilizar grandes projetos urbanos (GIELEN, TASAN-KOK, 2010). Na concertação, são inseridas obrigações (execução de infraestrutura, de 
habitação social, etc.) a cargo dos empreendedores, como contrapartidas ao direito de construir, que se desenvolvem ao longo de anos, pois os projetos são complexos, envolvem grandes investimentos e são baseados na expectativa de atraírem novos negócios e residentes para a área. No entanto, a discricionariedade é limitada por diretrizes ambientais da Comunidade Europeia ${ }^{2}$, dentre as quais se destaca a avaliação ambiental estratégica dos planos e dos projetos ${ }^{3}$, sem prejuízo da elaboração de EIA/RIMA (LANCHOTTI, 2014; OLIVEIRA, 2011). Além disso, em alguns países, como a Espanha, os Planos Urbanos definem os elementos estruturantes dos sistemas de redes públicas, com o objetivo de proporcionar um serviço integral, e estabelecem critérios para a conformação espacial de áreas homogêneas ${ }^{4}$, que servem como diretrizes fundamentais para a avaliação de projetos. Mesmo na Inglaterra, que adota a figura do development agreement, há critérios específicos que norteiam a negociação, movidos pela ideia da sustentabilidade ambiental e para promover a captura da valorização imobiliária decorrente do projeto (GIELEN, 2010).

Tais práticas contratuais são pouco teorizadas no Brasil (REISDORFER, 2014), e as análises efetuadas em uma perspectiva crítica focam na articulação público-privada (HARVEY, 2005; FREITAS, 2016; COTA, 2013). A presente pesquisa busca contribuir para 0 aperfeiçoamento do processo decisório concertado, apontando a importância dos instrumentos de avaliação prévia e integrada de impactos e de seu monitoramento ex post. Defende que sua falta compromete a sustentabilidade ambiental dos projetos e da cidade e forma um mosaico desencontrado de empreendimentos com infraestrutura insuficiente para absorver os impactos negativos sinérgicos e cumulativos, que afetam a mobilidade urbana, a drenagem, a paisagem, etc. Por força do Estatuto da Cidade, as externalidades negativas (ARAGÃO, 1997) devem ser internalizadas pelo empreendedor, com amparo no princípio da justa distribuição dos ônus e benefícios da urbanização (VIZZOTTO, 2018).

Não se adota a avaliação ambiental estratégica no país, o EIA/RIMA e o Estudo de Impacto de Vizinhança não têm o escopo de analisar efeitos sinérgicos de múltiplos empreendimentos em um mesmo território e se caracterizam por serem pontuais. Ainda, a conciliação dos diversos empreendimentos na paisagem urbana, de tal forma assegurar a harmonia entre os projetos, torna-se extremamente dificultada, pois o empreendimento é avaliado na escala do lote; e, em virtude dos direitos proprietários, cada um constrói o que quiser, de acordo com o regime do Plano Diretor. Por isso, no contexto da concertação urbanística, à falta de estudos urbanos abrangentes e de regras no Plano Diretor que imponham a integração entre os projetos, cada projeto é analisado isolada e discricionariamente, salvo se o Município adotar a figura da

2 A Diretiva 2011/92/UE, do Parlamento e do Conselho, refere-se à avaliação das repercussões de determinados projetos públicos e privados sobre o meio ambiente. Foi atualizada pela Diretiva 2014/52/UE. Ver o conteúdo das diversas diretivas com conteúdo ambiental no site https://europa.eu/european-union/topics/environment_pt, acesso em 10 de abril de 2019.

3 Ver como exemplo a Avaliação Ambiental Estratégica do Plano para definição da localização do cemitério de Madrid. Disponível em Http://www.madrid.org/es/transparencia/sites/default/files/regulation/documents/estudio_de_evaluacion_ambient al_estrategica.pdf , acesso em 09 de abril de 2019. Ver, ainda Plan General de Manzanares el Real (Madrid). Documento de Avance, Abril, 218.

${ }^{4}$ No art. 36 da Lei de Solo da Comunidade de Madrid consta a definição de que as redes públicas são o conjunto dos elementos das redes de infraestrutura, equipamentos e serviços públicos, que se relacionam entre si com a finalidade de proporcionar um serviço integral. 
operação urbana consorciada, que tampouco tem sido imune a críticas (FIX, 2011, FREITAS, 2016, OLBERTZ,2011).

\section{PRÁTICA DA CONCERTAÇÃO URBANÍSTICA EM PORTO ALEGRE}

Em Porto Alegre, a concertação é concretizada através de um termo de compromisso ${ }^{5}$, com natureza de título executivo extrajudicial, em que são previstas as obrigações do empreendedor e do Município para a viabilização do empreendimento e sua compatibilização com a infraestrutura urbana. Por parte da Prefeitura, constam obrigações relacionadas à desapropriação de áreas para implantação ou ampliação de vias públicas, em um contexto de grande discricionariedade administrativa, pois não há previsão dos critérios e padrões destas obrigações, dos procedimentos para negociação e posterior monitoramento e reavaliação das obrigações.

Conforme o atual Plano Diretorb, a concertação precede o licenciamento de Projetos Especiais de Impacto Urbano de $2^{\circ}$ Grau, que são listados no Anexo 11.2 do Plano. Dentre as tipologias, têm-se aeroporto, centro comercial com área adensável superior a $10.000 \mathrm{~m} 2$, centro cultural com área adensável superior a $5.000 \mathrm{~m} 2$, parque temático, shopping center, casos que impliquem solicitação de flexibilização de padrões urbanísticos, etc.(art.61, II,"a", PDDUA,com a alteração da LC 646/10).

Quando de sua previsão original no Plano Diretor de 1999, havia a especificação de zonas da cidade que poderia receber estes projetos. Com a alteração do Plano, em 2010, qualquer área da cidade pode receber projetos especiais, desde que o terreno tenha as dimensões previstas na legislação. Nestes casos, a aprovação do projeto urbano passará "por acordos programáticos estabelecidos com o Poder Público, tendo como referência os padrões definidos no Plano Regulador" (art.23).

A avaliação se dá no contexto de um estudo de viabilidade urbanística (EVU) e a participação social limita-se à análise pelo Conselho do PDDUA ${ }^{7}$, salvo nos casos de EIA/RIMA, quando se realizam audiências públicas. Quanto ao processo administrativo, 0 EVU tramita por várias secretarias que emitem diretrizes técnicas, que passarão a compor o futuro contrato. O cumprimento das obrigações, por sua vez, é condição para a emissão do "Habite-se".

Desde o ano de 2013, quando o Município passou a publicar os termos de compromisso firmados ${ }^{8}$, mais de duzentos projetos urbanos espalhados por toda a cidade e de diversas tipologias foram precedidos de negociação. Obras viárias, execução de praças e drenagem são o principal objeto dos termos de compromisso e sua exigência é feita conforme estudos custeados pelo empreendedor para o caso concreto. O Município não dispõe de planos abrangentes que possam orientar a análise técnica e se contrapor ao que é informado pelo empreendedor.

No caso da Macrozona 3, objeto do estudo de caso, ao longo da Av. Nilo Peçanha, a partir da implantação do Shopping Iguatemi nos anos 80, que sofreu sucessivas ampliações, foram implantados diversos projetos urbanos de grande porte, todos polos geradores de tráfego que foram negociados caso a caso, dentre os quais se assinalam uma universidade (UNISINOS), o shopping Astir, a ampliação do colégio Anchieta, um

\footnotetext{
5 Inspirado no termo de ajustamento de conduta previsto no art. 5ㅇ, §6ㅇ, da Lei 7347/85.

6 Os projetos especiais estão disciplinados pelo art. 56 e seguintes do PDDUA (LC 434/99, revisada pela LC 646/2010).

7 Conselho do Plano Diretor de Desenvolvimento Urbano Ambiental

8 Disponíveis em:http://www2.portoalegre.rs.gov.br/pgm/default.php?p_secao=537, acesso em09 de abril de 2019.
} 
hipermercado (Bourbon Country) e uma série de prédios residenciais, com flexibilização de altura. Salvo no caso da UNISINOS e da ampliação do Iguatemi, em que se exigiu EIA/RIMA, os demais empreendimentos foram licenciados apenas com laudo de cobertura vegetal e estudo de tráfego.

Figura 1 - Projetos Especiais da Macrozona 3

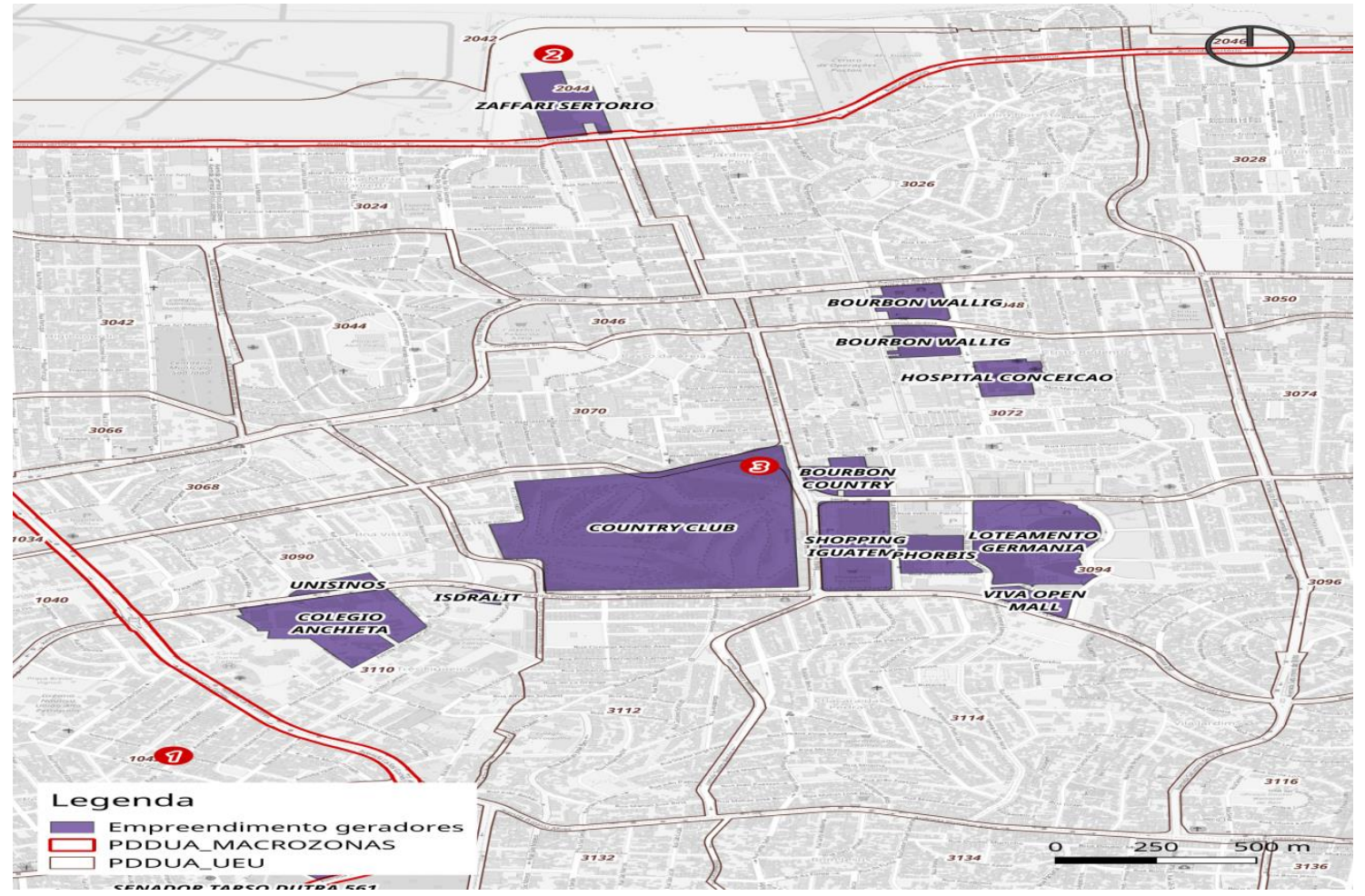

Fonte: STEIGLEDER, 2019

Além da ausência de estudos integrados, o que compromete a proporcionalidade entre as medidas mitigatórias previstas e os impactos efetivos, detectou-se que o Município se responsabiliza por desapropriações, voltadas à ampliação de vias, sem dispor de recursos orçamentários, o que concorre para a posterior não execução das contrapartidas viárias pelo empreendedor. Além disso, não há mecanismos de avaliação da valorização imobiliária decorrente da flexibilização da legislação (VIZZOTTO, 2018), o que também impede a justa distribuição dos ônus e benefícios da urbanização. Por fim, as obrigações fixadas são desacompanhadas de garantias reais ou fidejussórias, sendo a retenção do habite-se, atualmente, $\bigcirc$ único recurso que pressiona 0 empreendedor ao adimplemento.

Uma vez concluído o projeto, os impactos não são monitorados e novos empreendimentos são licenciados como se não estivessem inseridos em um todo maior, conforme uma lógica que hipertrofia o direito de construir, em detrimento da observância das funções sociais da cidade. 


\section{CONCLUSÕES}

A concertação urbanística em Porto Alegre se intensificou desde a última revisão do PDDUA, e vem resultando na implantação de projetos urbanos fragmentados, que não contam com integração na paisagem e na infraestrutura, cuja análise para fins de aprovação por parte do Poder Executivo não é precedida de instrumentos de avaliação de impacto ambiental e urbanísticos abrangentes, capazes de proporcionar uma interpretação integrada e harmônica do território. Carece-se, na legislação, da avaliação ambiental estratégica, a exemplo da experiência europeia, em que se analisam os impactos ambientais de planos e projetos urbanos, sob a condição de uma série de diretrizes de conteúdo ambiental. Portanto, embora a prática proporcione flexibilidade ao planejamento urbano, da forma como ocorre, em Porto Alegre, tende a favorecer exclusivamente o interesse do mercado, em detrimento do desenvolvimento urbano sustentável, pois inexistem critérios claros, que especifiquem as medidas mitigadoras, compensatórias e contrapartidas devidas pela flexibilização da lei e consequente valorização imobiliária, de tal forma a evitar a excessiva discricionariedade administrativa que se dá nas análises casuísticas.

\section{REFERÊNCIAS}

ARAGÃO, Maria Alexandra Souza. O princípio do poluidor-pagador: pedra angular da política comunitária do ambiente. Coimbra: Universidade de Coimbra, Coimbra Editora, 1997.

BRASIL. Estatuto da Cidade - Lei n. 10257, de 10 de julho de 2001. Regulamenta os arts. 182 e 183 da Constituição Federal, estabelece diretrizes gerais da política urbana e dá outras providências. Diário Oficial da União. Brasília, DF, 10 jul. 2001. Disponível em: <http://www.planalto.gov.br/ccivil_03/leis/leis_2001/l10257.htm>. Acesso em: 10.04.2019.

COTA, Daniela Abritta. A parceria público-privada na política urbana recente. Reflexões a partir da análise das operações urbanas em Belo Horizonte. Rio de Janeiro: Letra Capital, 2013.

CORREA, Jorge André Alves. Contratos urbanísticos. Concertação, contratação e neocontratualismo no direito do urbanismo. Coimbra: Almedina, 2009.

FIX, Mariana. Financeirização e transformações recentes no circuito imobiliário no Brasil. Tese de Doutorado. Universidade Estadual de Campinas, Instituto de Economia, Campinas, 2011.

FREITAS, Daniel Medeiros de. Desvelando o campo de poder dos grandes projetos urbanos da região metropolitana de Belo Horizonte. Tese de Doutorado. Escola de Arquitetura da UFMG, 2016.

GIELEN, Demetrio Muñoz \& TASAN-KOK, Tuna. Flexibility in Planning and the Consequences for Public-value Capturing in UK, Spain and the Netherlands. European Planning Studies, vol. 18, n. 7, july 2010.

GIELEN, Demeterio Muñoz.Capturing value increase in urban redevelopment. A study of how the economic value increase in urban redevelopment can be used to finance the necessary public infrastructure and other facilities. Doctoral Tesis. Radboud University Nijmegen, 2010. 
HARVEY, David. A produção capitalista do espaço. São Paulo: Annablume, 2005.

LANCHOTTI, Andressa de Oliveira. Evaluación de Impacto Ambiental y Desarrollo Sostenible. Belo Horizonte: Arraes Editores, 2014.

MADRID, Plan General de Manzanares. Documento de Avance, tomos I e II. Abril, 2018.

OLBERTZ, Karlin.Operação urbana consorciada. Belo Horizonte: Editora Fórum, 2011.

OLIVEIRA, Fernanda Paula. A discricionariedade de planeamento urbanístico municipal na dogmática geral da discricionariedade administrativa. Coimbra: Almedina, 2011.

REISFORFER, Guilherme Dias. Direito urbanístico contratual. Dos atos negociais aos contratos de gestão urbana. Rio de Janeiro: Lumen Juris, 2014.

SOUZA, Marcelo Lopes de. Mudar a cidade. Uma introdução crítica ao planejamento e à gestão urbanos. Rio de Janeiro: Bertrand Brasil, 2015.

UNIÃO EUROPEIA. Diretiva 2001/42/CE do Parlamento Europeu e do Conselho.

VIZZOTTO, Andrea Teichmann. A efetividade da justa distribuição dos ônus do processo de urbanização por meio da recuperação de mais-valias urbanaș: Estudo do Shopping Center Iguatemi em Porto Alegre, 1983-2016. Tese de Doutorado. Programa de PósGraduação em Planejamento Urbano e Regional. Faculdade de Arquitetura. UFRGS, 2018.

SILVA, R. N.; OLIVEIRA, R. Os limites pedagógicos do paradigma da qualidade total na educação. In: CONGRESSO DE INICIAÇÃO CIENTíFICA DA UFPE, 4., 1996, Recife. Anais eletrônicos... Recife: UFPE, 1996. Disponível em: <http://www. propesq. ufpe.br/anais/anais/educ/ce04.htm>. Acesso em: 21 jan. 1997.

SILVA, T. F. L.; CARVALHO, M. M.; MELHADO, S.B. Estudo de caso sobre o impacto da qualidade da informação em projetos industriais. In: SIMPÓSIO BRASILEIRO DE QUALIDADE DO PROJETO NO AMBIENTE CONSTRUÍDO, 3.; ENCONTRO BRASILEIRO DE TECNOLOGIA DE INFORMAÇÃO E COMUNICAÇÃO NA CONSTRUÇÃO, 6., 2013, Campinas. 